\title{
ISSUES OF WOMEN HEALTH IN NON-MUSLIM COMMUNITY OF KARACHI, PAKISTAN: A QUALITATIVE SURVEY
}

\author{
Khalid Mahmood \\ Department of Pakistan Studies, Allama Iqbal Open University, Islamabad, Pakistan
}

\begin{abstract}
Background: The women from non-Muslim community of Karachi have to face several issues regarding their health. The objective of this study was to find out the issues regarding the women health in non-Muslim community of Karachi and to provide suggestions in this context.

Materials \& Methods: This qualitative survey was conducted at Pakistan Study Center, University of Karachi, Pakistan from July 2011 to December 2011. Eleven Non-Muslim populated areas of Karachi were selected. The primary data was collected through structured interview schedule, including 15 open ended questions. One doctor from each cluster of the eleven minority populations was interviewed. The responses were noted on a notebook. The theme was to understand the health issues faced by women around fourteen concepts; provision of food to boys and girls, health of girls before marriage, health of girls after marriage, side effects of early age marriages, women's health during pregnancy, role of midwife, presence of non-qualified practitioners, problems during maternity, concept of family planning, health facility during emergency, weight of children at the time of birth, mother feed for the children, role of dirty and polluted atmosphere, and diseases due to reserved professions.
\end{abstract}

Results: There was a lack of awareness in the non-Muslim families of Karachi regarding provision of equal food to their children on the basis of sex. The physical health of girls before marriage was not good in these families. After marriage they are also at risk of mental illness due to poverty, illiteracy, uncomfortable residential units and having limited access to the lady doctors. The overcrowded houses and polluted atmosphere also affects badly their physical health.

Conclusion: The non-Muslim women are deprived from health facilities due to socio-economic problems. It is the dire need to provide health education to the non-Muslim women in their settlements. Moreover, Health care facilities may be provided by establishing Basic Health Units, Rural Health Centers, Maternal \& Child Health centers in these areas as per population density.

KEY WORDS: Women; Health; Survey; Women's Health; Boys; Girls; Marriage; Disease; Pregnancy; Food.

Cite as: Mahmood K. Issues of women health in non-Muslim community of Karachi, Pakistan: a qualitative survey. Gomal J Med Sci 2020 Jul-Sep; 18 (3):93.8. http://doi.org/10.46903/gjms/18.03.852

\section{INTRODUCTION}

Women and minority groups cannot be neglected in any society. According to the Pakistan Bureau of Statistics, women are 48 percent of the total population. ${ }^{1}$ In addition, the literacy rate in women is only 32 percent, contrary to 54.8 percent in men. ${ }^{2}$ The literacy among the minority women is much

\section{Corresponding Author:}

Dr. Khalid Mahmood

Lecturer, Department of Pakistan Studies

Allama Iqbal Open University

Islamabad, Pakistan

E-mail: khalid.mahmood@aiou.edu.pk

Date Submitted: 09-07-2019

Date Revised: $\quad 30-04-2020$

Date Accepted: $\quad 14-05-2020$ lower as compared to the women of majority Muslim population. Due to lack of education, they don't know the methods of maintaining their good health. Therefore, women in general have been facing a variety of issues concerning their health.

Pakistan is one of the developing countries situated in South Asia. ${ }^{3}$ According to the Asian Development Bank, there remained a great movement for the empowerment of women in the country and many associations had been working for the uplifting of women. ${ }^{4}$

Sindh is the second largest populated province of Pakistan after Punjab and Karachi is the largest populated city of Pakistan; where multi-regional, multi-language, multi-cultural, multi-ethnic and multi-religion citizens are settled..$^{5}$ The public have many facilities in this city but the citizens of the same 
city have to face a large number of problems due to its un-controlled population.

The large number of non-Muslim citizens in Karachi belongs to under-privileged class and they don't have the suitable health facilities as compared to the majority group. One of its main reasons is that the non-Muslim citizens have been living in separate settlements in Karachi city. Narien Pura is the largest historical settlement of the Hindus, Christians and Sikhs in Karachi. Like this, Christian Town and Easa Nagri are the congested settlements of Christians. On the other hand, Chanesar Goth and Jogi Moar are the largest Hindus' populated slums. Most of the minorities' settlements are situated at the corners of the Karachi city and far from the central or old city area. Due to this, there are very less health facilities in these areas and minority women specially have to face more issues regarding their health. According to Census report of 1998, Karachi Division/ City had the population of 9.58 million, including 3.55 percent non-Muslims.

Jalal-ud-Dinand Khan have found that like many other developing countries, in Pakistan the girls have less access to good food, better health and right of education contrary to boys. ${ }^{6}$ Furthermore, after marriage women are treated as property of their husbands in the under-developed countries.

The Constitution of Pakistan 1973 has awarded the right of equality to all citizens with no difference on the bases of sex. It also provides equal participation of women in all areas of life and it was made clear that there will be no discrimination to provide government employment. ${ }^{7}$

On the other hand, Pakistan's Economic Survey (2014-15) shows the high rate of maternal mortality that was $170 / 100,000$ and its main reasons were lack of education, food insecurity, and insufficient nutrition and less funding allocation for this purpose. ${ }^{8}$ Unavailability of suitable health facilities are a general problem all over the country. According to the $\mathrm{Pa}$ kistan's Economic Survey (2015-16) there was one doctor for 1,038 people while the total number of registered doctors was 184,711 in all over the country. ${ }^{9}$ Pakistan's Economic Survey (2016-17) reveals that the situation has improved to some extent as today, the ratio of doctor and population stands at 1: 997.10

The Universal Declaration of Human Rights says in Article 2 that "Everyone is entitled to all the rights and freedoms set forth in this Declaration, without distinction of any kind, such as race, colour, sex, language, religion, political or other opinion, national or social origin, property, birth or other status". Article 24 of the same declaration says that "Everyone has the right to rest and leisure, including reasonable limitation of working hours and periodic holidays with pay". ${ }^{11}$

In the light of the above facts, women in Pakistan can- not enjoy their life particularly those who belonged to minority group. Normally they are exploited in their homes due to being women and outside from home due to being non-Muslim. They do care for the house, bring up of their children, work hard for earning but are deprived from balanced diet to keep their selves healthy.

The objective of this study was to find out the issues regarding the women health in non-Muslim community of Karachi and to provide suggestions in this context.

\section{MATERIALS AND METHODS}

This qualitative survey was conducted at Pakistan Study Center, University of Karachi, Karachi, Pakistan from July 2011 to December 2011. The universe of this research included non-Muslim women of Karachi division (city). Eleven clusters of non-Muslim populated areas were selected for the study, including Tesar Town, Naarin Pora, Christian Town, Jogee Moar, Eesa Nagrre, Mari Poor, Chanesor Goath, D. Selva Town, Eidu Goth, Sha-Rasul Colony and Pahlewan Goth, where Hindus, Christians and Sikhs citizens have been living for a long time.

The primary data was collected through structured interview schedule, including 14 open ended questions. One doctor from each cluster of the eleven minority populations was interviewed. The responses were noted on a notebook. The theme was to understand the health issues faced by the non-Muslim minority women around fourteen concepts; provision of food to boys and girls, health of girls before marriage, health of girls after marriage, side effects of early age marriages, women's health during pregnancy, role of midwife, presence of non-qualified practitioners, problems during maternity, concept of family planning, health facility during emergency, weight of children at the time of birth, mother feed for the children, role of dirty and polluted atmosphere, and diseases due to reserved professions.

\section{RESULTS AND DISCUSSION}

The researcher documented some facts through interviews with the doctors working in the minority population's settlements. Some important issues are being discussed regarding the health of non-Muslim women of Karachi.

\subsection{Provision of food to boys and girls}

It was found in eight out of eleven areas that the parents had no discrimination in their children regarding their sex for the nutrition. The non-Muslim citizens cannot afford the expenses of their offspring due to poverty. They are the poorest due to unavailability of job resources. The non-Muslim citizens do not have the resources to provide nutritious food to their children. The parents have no difference between the boys and girls but it is fact that the children are deprived from the healthy food. 
On the other hand, discrimination was observed to some extent among boys and girls in three minority areas out of eleven. Girls were neglected by their parents in some families by providing less food than the boys. The boys are not only provided better food but preferred in all matters in the home. The girls are ignored at their homes due to ignorance of their parents. They think that the boy will give earning to their parents. The illiterate mothers provide less milk to their daughters contrary to sons.

\subsection{Health of girls before marriage}

According to the opinion of doctors, the majority of unmarried girls in non-Muslim community have various issues regarding their health. They remain deprived of the vaccination and better food. Before their marriages, the girls work hard in their home; therefore, they are suffered from anemia, depression, leucorrhoea and other deceases.

\subsection{Health of girls after marriage}

The married women in non-Muslim families have to face not only social problems but also economic and health issues. Anemia is the major issue of virgin girls but after marriage, their life becomes more complicated as they cannot avail balanced food. As a result their health problems increase rapidly. Their life becomes bitter due to poverty and negative social behaviors. Due to these problems, the period of their pregnancies remains complicated as they cannot afford a single cup of milk in a day.

According to one of the interviewed doctors, the problems of non-Muslim girls remain same after getting marriages. There is no change in their lives except shifting from one home to another. They are deprived from pure drinking water and healthy food. Another doctor had the opinion that the non-Muslim girls change their life pattern and culture after getting marriage. Their social status suffers badly and they are considered lower compared to men as this is the part of their culture due to ignorance and poverty. They even don't know about their personal health issues and take medicines without the consultation of the doctors. They have been in dangerous situation after marriages as an un-ending chain of child-birth gets started for all of their remaining life. Another issue is that the health of married girls suffered badly after their marriages due to domestic disputes. They have the problems regarding their health due to various reasons including their large scale offspring, low family income and living in small residential units.

\subsection{Side effects of early age marriages}

Particularly, the girls are suffered from anemia before marriage and they are married in early ages without consulting their opinion. After the marriage, their poverty remains as such, which may result in increasing bitterness between husband and wife, leading to divorce in some cases. The early age marriage is a great tragedy for the non-Muslim girls.
A large number of problems are taking birth due to early marriage. After marriage, living in poverty and having negative social attitudes are the reasons of their bad health. Due to socio-economic crisis, the minority women avoid consulting doctors for medical treatment.

\subsection{Women's health during pregnancy}

The Christians and Hindus minority population of Chanesar Goth have the facility of Jinnah Postgraduate Medical Centre (Hospital) nearby, however, due to ignorance they seldom visit to gynecologist during pregnancy and consult to doctor only once at the time of delivery. Most of the minority women don't know up-to few months that they have been pregnant. So they don't have idea to consult the lady doctors. After conceiving pregnancy, a very large ratio of these women doesn't have balanced diet. One of the problems of minority women is that they don't know the method of family planning, often they conceive their pregnancy very soon and then they utilize the practice of abortion that makes more complications regarding their health. They visit to midwife to deliver their baby. In case of complications, they consult doctor at the eleventh hour. Sometimes the new born baby needs oxygen and the baby may be shifted to the hospital along with mother in this critical situation but then the doctor may not help them fully.

\subsection{Role of midwife}

Most of the non-Muslim women avail the midwife's advice during their pregnancy and for the delivery. Sometimes due to complications, the midwife is unable to deliver the child properly; some of the women may die during child birth. In spite of this, the people prefer to these midwives. One of the main reasons of this practice is that these families have blood relations or strong social connections with these midwives and call them for treatment, but at the bad time they blame their fortune if the mother loses her life. The people visit to doctors seldom and if the doctor informs them that the baby would be delivered through operation; they leave the doctor and consult to the midwife because these people wish to deliver child thorough normal ways instead of surgical procedure. They look at midwife for this purpose and if the baby is out of position in the mother womb; they ask midwife to make its angle at correct position. In these situations, the majority women follow the advices of midwife and don't visit the hospitals. According to a doctor from Mari Pur, the minority women have no access to doctors during their pregnancies and there is no public sector maternity home. Particularly, the women of Hindu community are on the compassion and support of midwives. There is a dire need of taking urgent measures by the government.

Issue of lack of nutrition is also one of the problems faced by Hindu women during pregnancies. The 
poor people cannot take milk and eggs; as a result, mother and child both remain weak. If the hospital is far from the minority areas, the people cannot arrange the shifting of pregnant ladies to the hospitals as they have no money for transportation.

\subsection{Presence of non-qualified practitioners}

There are non-qualified practitioners everywhere in the minority areas. Taisar Town has the population of almost one lac and there is not a single public sector hospital or maternity home. The people are bound to visit untrained practitioners. These practitioners have established maternity homes and clinics inside their own homes and their wives generally play the role of lady doctors. They inoculate the ladies directly in their veins to deliver the child immediately without any ultrasound but this is the highly risky process of delivering child as many women die during this process. Almost, in all over the Karachi division, the non-qualified practitioners are making their business and there is no one to stop or bane them.

\subsection{Problems during maternity}

Unavailability of good food, not getting access to the lady doctor during pregnancy period and consultancy with midwives makes the process of child birth more complicated. At the end, they have to visit Jinnah Postgraduate Medical Center situated in the main city at the distance of $40-50 \mathrm{~km}$ from Eido Goth, Jogi Moar and Taisar Town; often it takes more than 3 hours due to road jams. Sometimes the mother delivers the child inside the taxi or ambulance, sometimes the mother loses her life before reaching hospital and often she has to bear pain for a long time on the roads.

\subsection{Concept of family planning}

The majority of non-Muslim citizens are senseless of maintaining gap of certain period between the birth of previous and the next child. Therefore, in most of the minority populated areas of Karachi, there are a large number of children in each house. The minority families don't opt family planning at the start and they wish to produce minimum four to five children in the very short period of time after their marriages. Therefore they totally concentrate to the child birth instead of birth control in early period. They get realize after making a large family as they cannot afford to bring up their children and then use condom, injection or other contraceptive.

Due to minimum gap in the children; women suffer from deficiency of iron and other minerals. Due to continued child birth, the population has increased in minority populated areas and there are 10 to 12 children in each family while more than one or two families have been living in single house of one or two rooms. In many areas, the people don't have gap of 2 years; as they don't know the basic knowledge of family planning methods.

\subsection{Health facilities during emergency}

There is no health facility during emergency in most of the minority populated areas. They have to approach Jinnah Postgraduate Medical Centre or Abbasi Shaheed Hospital of the city in case of emergency. Due to traffic jam and long distance the public have to spend more than three hours to reach the hospital especially from the areas of Taisar Town, Jogi Moar, Mari Pur and Eido Goth. The Christians of Easa Nagri have limited financial resources in normal situation for treatment. Moreover, poverty is the obstacle in taking treatment, ambulance is not available in emergency, women have no access to lady doctor, and these health problems are increased day by day. However, a few with better financial conditions consult to private hospitals while a large number of non-Muslims do self-treatment at homes. Often, the people visit government hospitals but there is always rush of patients.

\subsection{Weight of children at the time of birth}

There is no concept of contraceptive measures and the men of minority groups are proud of their more number of children. The child can't achieve required food before birth. At all over the minority areas of Karachi, 30 percent new born babies have their weight normal but 70 percent have less than normal weight at the time of birth. Due to shortage of food the women have suffered anemia during pregnancy and when the mother is not healthy, she cannot produce a healthy baby. The mother cannot produce her milk in sufficient quantity; therefore children cannot get their mother feed properly. The parents can't purchase the artificial milk for children while the animal milk does not match to the infants; as a result the infants of minority women often remain sick as they have mostly stomach and chest infections.

\subsection{Mother feed for the children}

The infants have low weight as there is no gap in the child-birth; but after the birth, infants also don't have proper milk to fulfill the requirements. The other problem of children is that the mothers don't have their sufficient milk for children. Approximately 80 percent children get mother feed that is insufficient for them; however 20 percent children get artificial feed through feeder and the milk is non-standard. The mothers can purchase the artificial milk through their struggle but they can't mix the proper quantity of milk and water. Due to ignorance the mothers usually don't boil the feeder; as a result, the children get germs into their bodies regularly and that affects their health badly.

\subsection{Role of dirty and polluted atmosphere}

According to the local doctors of the minority populated areas; abundance of mosquitoes, worse condition of houses, presence of dirt inside and outsides of houses, availability of chemical mixture 
water and absence of common sense in the public are main reasons of health issues. Many people in these areas are suffering from asthma and irritation due to polluted atmosphere. The most important reason is ignorance as the people never used boil water for drinking while the dirty water is supplied through water supply system and tanker mafia. This dirty water is the cause of stomach and lever diseases. The Christians of Easa Nagri don't have basic knowledge of safety measures and they can't afford the treatment in case of diseases.

The local doctors have discussed some issues connected to health in the minority areas including congested population, small and air-less houses, damage sewerage system, large scale production of mosquitoes, dirty water, non-standard milk, use of un-packed and fried items of food, insufficient food, uses of dirty utensils and family conflicts. Moreover, a very large numbers of non-Muslim citizens are connected to cleaning work and they get germs from garbage while there is no proper arrangement of preventive measures.

There are some specific reasons that cause the diseases in non-Muslim families including use of drugs, joblessness, and no activities for youth, absence of parks and depression due to shortage of money. Therefore the non-Muslim people, particularly the women are suffering from various diseases.

\subsection{Diseases due to reserved professions}

Non-Muslims are human being like the other people of country and they may suffer from any disease like other people of society; however they can get some special diseases easily like asthma, flu, stomach diseases and hepatitis $B$ and $C$ due to their specific professions like cleaning work. In most of the minority areas, many non-Muslim women have to face strong seasonal conditions especially those who beg all the day in sunlight and the women who are connected to sweeping work. Due to reserved professions when the people come back to home at the evening after sweeping, they wash their hands with simple water without using soap, therefore the germs remains with their hands; these germs are transferred into the bodies during taking food and as a result these people are suffered from many diseases. A very strong reason of problems regarding health is the absence of government interest in the minority populated areas because government has never taken sufficient measures to solve the health issues of non-Muslims citizens.

\section{CONCLUSION AND RECOMMENDATIONS}

The non-Muslim women cannot avail better treatment due to their poverty, cultural and socio-economic issues. Their health remains poor since birth because they can't achieve proper mother feed. They have to face difficulties before and after marriages.
They get diseases since their childhood and are neglected by their parents but after their marriage their social circumstances remains same; and they have to work hard for their families. The non-Muslim girls are married by their parents at very early age due without their consent.

The following measures are recommended to solve the issues of women health in the non-Muslim communities of Karachi.

1. The government has the basic responsibility to provide health facilities equally to all citizens of the country. It is the dire need to provide health education to the non-Muslim women in their settlements.

2. The non-Muslim Ladies Health Workers should be appointed in the minority populated areas for the removal of problems regarding health of non-Muslim women. Moreover, Health care facilities may be provided by establishing Basic Health Units, Rural Health Centers, Maternal \& Child Health centers in these areas as per population density.

\section{REFERENCES}

1. Government of Pakistan. Population of Pakistan. Islamabad: Pakistan Bureau of Statistics. No date [cited 2018 June 13]. Available from: http:// www.pbs.gov.pk/sites/default/files/other/pocket_book2006/2.pdf

2. Government of Pakistan. Census 1998: Population by religion. Islamabad: Statistics Division, Population Census Organization; 2004. [cited 2018 March 22]. Available from: http://www.pbs. gov.pk/content/population-religion

3. Statement of Pakistan. No date [cited 2018 July 16]. Available from:https://www.thegef.org/sites/ default/files/council-meeting-documents/statement_of_Pakistan_4.pdf

4. Asian Development Bank. Women in Pakistan: Country Briefing Paper. Asian Development Bank; July 2000. No date [cited 2018 May 25]. Available from: https://www.adb.org/documents/ women-pakistan-country-briefing-paper

5. Government of Pakistan. Population of Pakistan. Islamabad: Pakistan Bureau of Statistics. No date [cited 2018 May 25]. Available from: http://www. census.gov.pk/SINDH/KARACHI.html

6. Jalal-ud-Din M, Khan M. Socio economic and cultural constraints of women in Pakistan with special reference to Mardan district, NWFP Province. Sarhad J Agric 2008; 24(3):485-93.

7. Govt. of Pakistan. Constitution of Pakistan 1973. Islamabad: Government of Pakistan. No date. Article 25, 27 and 37, [cited 2018 August 18]. Available from: http://www.na.gov.pk/uploads/ documents/1549886415_632.pdf

8. Government of Pakistan. Pakistan's Economic Survey (2014-15). Islamabad: Ministry of Finance 2015 237-9. [cited 2018 September 17]. Available 
from: http://www.finance.gov.pk/

9. Government of Pakistan. Pakistan's Economic Survey (2015-16). Islamabad: Ministry of Finance 2016 [cited 2018 August 29]. Available from: http://www.finance.gov.pk/

10. Government of Pakistan. Pakistan's Economic
Survey (2016-17). Islamabad: Ministry of Finance 2017. [cited 2018 September 11]. Available from: http://www.finance.gov.pk/

11. United Nations. Universal declaration of human rights [cited 2018 April 19]. Available from: http:// www.un.org/en/documents/udhr/

CONFLICT OF INTEREST

Authors declare no conflict of interest. GRANT SUPPORT AND FINANCIAL DISCLOSURE None declared.

Copyright (C) 2020. Khalid Mahmood. This is an Open Access article distributed under the terms of the Creative Commons Attribution-NonCommercial 4.0 International License, which permits unrestricted use, distribution \& reproduction in any medium provided that original work is cited properly. 